\title{
LA EVOLUCIÓN IDENTITARIA DE LAS POETAS EN ESPAÑOL DEL SIGLO XX: EL CONCEPTO DE FELICIDAD
}

\section{THE EVOLUTION OF IDENTITY IN SPANISH-SPEAKING POETS OF THE 20TH CENTURY: THE CONCEPT OF HAPPINESS}

\section{Raquel LANSEROS SÁNCHEZ \\ Universidad de León rlans@unileon.es}

Resumen: El presente artículo trata de analizar la evolución de la identidad personal de las poetas que han escrito en español durante el siglo XX a través del concepto de felicidad que éstas proyectan en sus poemas. Es indudable que el concepto de felicidad es mutable, como todo constructo cultural, por tanto se ha visto sometido a revisiones y modificaciones a medida que han ido cambiando las concepciones y prioridades de la sociedad a lo largo del siglo XX. En este sentido, se pretende analizar el modo en que las mujeres hispanohablantes han reflejado en su creación poética su propia comprensión del concepto de felicidad a lo largo del siglo XX, que supone un punto de inflexión histórico en la lucha por los derechos y la equidad jurídica y civil por parte de la población femenina. Para ello, nos fijaremos en poemas de seis poetas de la primera mitad del siglo XX -seis españolas y seis hispanoamericanas- Lucía Sánchez Saornil, Concha Méndez, Ángela Figuera Aymerich, Delmira Agustini, Juana de Ibarbourou y Dulce María Loynaz. Indeleblemente ligado a la contrucción identitaria, el concepto personal y colectivo de felicidad ha ido evolucionando con la incorporación de la mujer al ámbito público, de lo cual estas seis autoras suponen un inmejorable ejemplo.

Palabras clave: Poesía; felicidad; poesía en español; poetas españolas; poetas hispanoamericanas.

Abstract: The present article tries to analyze the evolution of the personal identity of the poets who have written in the Spanish language during the 20th century through the concept of happiness that they project in their poems. Undoubtedly, the concept of happiness is mutable, like any cultural construct, so it has been subject to revisions and modifications as the conceptions and priorities of society have changed throughout the 20th century. In this sense, we intend to analyze the way in which Spanish-speaking women have reflected in their poetic creation their own understanding of the concept of happiness throughout the 20th century, which represents a historical turning point in the struggle 
84 Tropelías. Revista de Teoría de la Literatura y Literatura Comparada, 30 (2018) Raquel Lanseros Sánchez

for civil rights and legal equity legal on the part of the female population. In order to attain our objectives, we will examine poems by six poets of the first half of the 20th century -six Spanish and six Hispanic Americans- Lucía Sánchez Saornil, Concha Méndez, Ángela Figuera Aymerich, Delmira Agustini, Juana de Ibarbourou and Dulce María Loynaz. Indelibly linked to identity construction, the personal and collective concept of happiness has been evolving with the incorporation of women in the public sphere. These six authors are an excellent example of it.

Keywords: Poetry; Happiness; Poetry in Spanish; Spanish Poets, Hispano-American Poets. 


\section{Tropelías. Revista de Teoría de la Literatura y Literatura Comparada, 30 (2018) \\ La evolución identitaria de las poetas en español del siglo XX: el concepto de felicidad}

\section{$\mathbf{I}$}

ntroducción

En su célebre libro de 1930 La conquista de la felicidad, el filósofo, matemático y escritor británico Bertrand Russell afirmaba lo siguiente, en referencia a la posibilidad de la felicidad en los tiempos contemporáneos (2002: 87):

Existen dos clases de felicidad, aunque, naturalmente, hay grados intermedios. Las dos clases a las que me refiero podrían denominarse normal y de fantasía, o animal y espiritual, o del corazón y de la cabeza. La designación que elijamos entre estas alternativas depende, por supuesto, de la tesis que se pretenda demostrar. A mí, por el momento, no me interesa demostrar ninguna, sino simplemente describir. Posiblemente, el modo más sencillo de describir las diferencias entre las dos clases de felicidad es decir que una está al alcance de cualquier ser humano y la otra sólo pueden alcanzarla los que saben leer y escribir.

Es evidente que la felicidad a la que nos referimos, en el caso de las poetas del siglo XX objeto de nuestro estudio ${ }^{1}$, cuya obra está escrita en español, pertenece a la segunda clase. Todas ellas son mujeres cultas, con una educación lectora sobresaliente, en la mayoría de los casos muy por encima de la media formativa que sus respectivas épocas tenían reservada a las mujeres. Todas ellas son, pues, personas que no sólo saben leer y escribir, sino que disfrutan especialmente de la realización de ambas actividades. Poetas cuyas obras reflejan una elevada dosis de creatividad, imaginación y pujanza intelectual.

Es indudable que la literatura, como ya expuso y profundizó Juan Carlos Rodríguez en un pormenorizado estudio (1990), inserta como está en el seno de una determinada sociedad y cultura, secunda y reproduce sesgos ideológicos, que son en muchos casos los predominantes. Pero la literatura posee asimismo la capacidad revulsiva de crear nuevos enfoques e introducir perspectivas diferentes en los parámetros sociales al uso, como han demostrado tantas obras literarias que han supuesto un antes y un después en las corrientes de pensamiento de muchas épocas. Lamentablemente, este segundo tipo de literatura, no convencional y redundante, sino crítica y subversiva, ha enfrentado históricamente un mayor número de dificultades para su difusión, debido a que los resortes de transmisión imperantes han sido siempre reacios al establecimiento de nuevas concepciones.

Ni que decir tiene que la literatura escrita por mujeres ha tenido tradicionalmente que enfrentarse a un doble filtro para poder alcanzar su merecido reconocimiento: por un lado, la naturaleza inconformista o no de su contenido literario; por otro, el rol subsidiario al que la sociedad patriarcal, hasta bien avanzado al siglo XX, relegaba a las mujeres. Esta realidad ha traído aparejada una enorme dificultad y exigencia a la hora de que la producción literaria de una mujer pudiese ser asimilada a las corrientes literarias canónicas. El siglo XX marcó, en este sentido, un punto de inflexión en la lucha por los derechos y la equidad jurídica y civil por parte de la población femenina. Una serie de

\footnotetext{
${ }^{1}$ Para la elaboración del presente trabajo, analizaremos brevemente algunos poemas de seis poetas contenidas en la antología Poesía soy yo. Poetas en español del siglo XX (1886-1960), publicada en 2016 por la editorial Visor Libros y de cuya edición crítica, prólogo y selección nos encargamos Ana Merino y yo.
} 
transformaciones sociales, propiciadas por la reivindicación incesante desde muchos colectivos, propiciaron una mayor igualdad -aunque todavía escasa e imperfecta- que permitió modificar parcialmente los restrictivos paradigmas sociales imperantes.

Dado su rol de transformadoras en el campo social y literario - ya iniciado por grandes poetas de siglos anteriores cuya obra abrió caminos de expresión y contribuyó decisivamente a la Historia de la Literatura- hemos seleccionado para el presente estudio seis poetas de España y de América Latina, nacidas entre finales del siglo XIX y principios del siglo XX. Ellas fueron pioneras en la construcción de una identidad propia a lo largo del siglo XX, ya no subsidiaria sino protagonista, que ha permitido a las mujeres un grado de emancipación física y mental anteriormente negado.

\section{Felicidad: un concepto mutable}

Uno de los rasgos de la identidad personal es el concepto de felicidad, tan voluble e intangible, cambiante a lo largo de la Historia y continuamente sometido a revisión. Es conveniente recordar que en la concepción de felicidad de cada individuo influyen, además de los factores culturales y sociales, otros personales de naturaleza tan variable como el temperamento, la edad, el carácter o la biografía. Por tanto, es muy interesante comenzar a mostrar el mapa de la poesía en lengua española escrita por mujeres durante el siglo XX a través del análisis de sus diversos conceptos de felicidad. Una cartografía donde pueden rastrearse desde las diferentes épocas, las distintas mentalidades sociales, las variaciones culturales geográficas y la propia personalidad, tan marcada por la respectiva experiencia vital.

Además, se puede rastrear la evolución de la identidad femenina a principios del siglo XX, un tiempo en que se produjo un marcado cambio en los roles sociales asignados a cada género. Como consecuencia, las aspiraciones de realización de las mujeres fueron abandonando progresivamente el ámbito doméstico para verterse en el público, conquistando nuevos espacios de proyección personal que han ido modelando la construcción de una sociedad más igualitaria. Es notorio en muchas de las poetas estudiadas un adelanto a su tiempo en este sentido, lo que las configura como pioneras no sólo en el campo literario, sino también social y cultural.

\section{Poetas españolas en la primera mitad del siglo XX}

Veamos tres poemas, con el fin de ilustrar nuestros propósitos, escritos respectivamente por tres poetas españolas cuyos inicios literarios tuvieron lugar en la primera mitad del siglo XX.

Lucía Sánchez Saornil nació en Madrid en 1895. Adherida desde sus inicios al movimiento ultraísta, publicó en las más importantes revistas de la vanguardia bajo el seudónimo de Luciano de San-Saor. Mantuvo una militancia política activa durante los años de la República, fundando poco antes del comienzo de la Guerra Civil la organización feminista libertaria Mujeres Libres. Murió en Valencia en 1970, donde había vivido desde 1954, tras un largo periodo de clandestinidad. 
En su poema "Avenida matinal"2, publicado por primera vez en 1929 en el número 7 de la revista Manantial, la poeta describe el sentimiento de felicidad que le provoca la mañana:

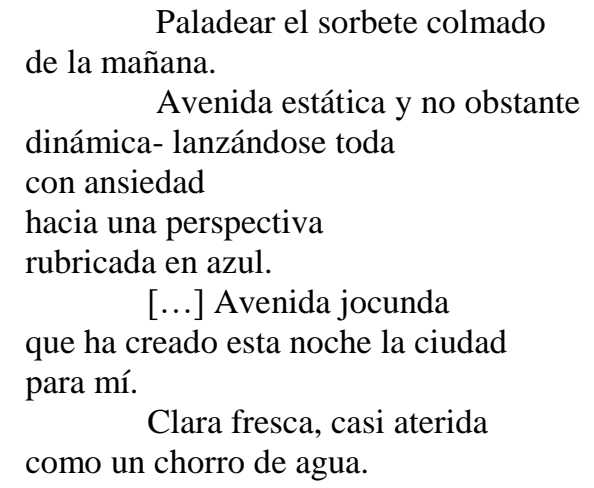

La sensación de estreno que proporciona un nuevo día es vívidamente descrita por SánchezSaornil, quien define ese prometedor momento del día como "sorbete colmado". La perspectiva de lo que aguarda es para la poeta una renovada promesa de felicidad, entendida como la mezcla equilibrada entre la estática y el dinamismo. El azul, color del mar y del cielo, se representa como un símbolo de futuro, de esperanza, de crecimiento. La avenida es adjetivada por la poeta como "jocunda", remarcando la sensación de placidez y bienestar. La transparencia del instante y la ilusión de un porvenir dichoso se resume en el verso final con la poderosa imagen del "chorro de agua", cuyo aterimiento no menoscaba la claridad de la confianza en el tiempo nuevo que se brinda.

Concha Méndez, poeta madrileña nacida en 1898, perteneciente al núcleo fundador de la Generación del 27, contribuyó decisivamente a la distribución de la obra de sus miembros, editando revistas como 1616 o Caballo verde para la poesía. Exiliada tras la Guerra Civil regresó a España en 1966, aunque continuó viviendo en México hasta su muerte, en 1986. En su poema "Ser", publicado en el libro Surtidor (1928), la poeta describe la existencia con grandes dosis de optimismo:

Ser.

Fábrica de ideas.

Fábrica de sensaciones.

¡Revolución de todos

los motores!

Ser y ser.

Energía continua.

Dinamismo.

Evolución.

Así siempre.

Y cerca de los astros.

¡Ser!

\footnotetext{
2 “Avenida matinal” fue recogido en el libro Poesía (1996), cuya editora fue Rosa María Martín Casamitjana y que incluye la obra dispersa e inédita de Lucía Sánchez Saornil.
} 
El poema rebosa de vocabulario entusiasta como revolución, energía, dinamismo, evolución. La percepción central que transmite sobre la vida es muy gozosa, una marcha hacia adelante que no cesa, plena de vigor y siempre cambiante. La poeta habla de ideas y de sensaciones, en consonancia con la unamuniana sentencia de "sentir el pensamiento y pensar el sentimiento", en un vivaz intento de plenitud. Cierra el poema con un verso definitivo, un complemento circunstancial de lugar que es esencial en la culminación de la existencia feliz: "cerca de los astros". Ser cerca de los astros, como metáfora de las altas aspiraciones, de la intención consciente de alejamiento de las bajas y mezquinas pasiones. Tender hacia lo alto como sinónimo del existir dichoso y pleno que Concha Méndez describe y comparte.

Ángela Figuera Aymerich, nacida en Bilbao en 1902, forma parte del llamado Triunvirato Vasco de la poesía de posguerra, junto a Blas de Otero y Gabriel Celaya. Catedrática de instituto, le retiran el trabajo y el título universitario por su afinidad con la causa republicana. Desde 1952 trabaja en la Biblioteca Nacional de Madrid, León Felipe escribió un prólogo para su libro Belleza cruel, que ganó el premio de poesía Nueva España, impulsado por la Unión de intelectuales en el exilio. En su conocido poema "No quiero", incluido en su primer libro Mujer de barro (1948), que reunía obra escrita en los años previos, Figuera Aymerich hacía una formidable descripción de todas las cosas para ella indeseadas. Por deducción, el lector sabe que la poeta aspira a lo contrario de lo que menciona:

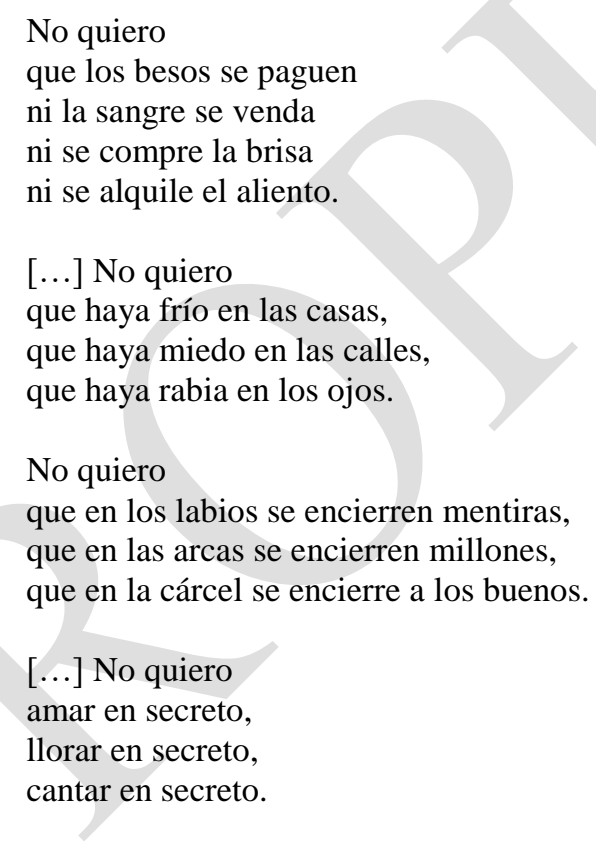

La felicidad, pues, se dibuja como un desiderátum en la que ni el amor ni la sangre ni la brisa ni el aliento estén sujetos a mercantilización. Un modo rotundo de afirmar su ambición de que la vida no esté sometida a los caprichos del dinero, de modo que todas las clases sociales sean dueñas de su dignidad. Del mismo modo, la poeta reclama un mundo más equitativo como premisa básica para la felicidad, donde no haya lugar para el frío, el miedo o la rabia que genera la injusticia. Clama también contra la cárcel que sufren los buenos e inocentes. Para la correcta contextualización de esta aspiración hay que recordar las circunstancias históricas en que fue escrito el poema, durante la década de los 
años cuarenta en España, cuando el régimen franquista oprimió y silenció sistemáticamente a sus detractores por todos los medios posibles. El último verso, "no quiero cantar en secreto", representa todo un homenaje a la libertad de expresión, condición imprescindible para la felicidad del poeta.

\section{Poetas latinoamericanas en la primera mitad del siglo $\mathrm{XX}$}

Veamos a continuación tres poemas, para seguir ilustrando nuestros propósitos, escritos respectivamente por tres poetas latinoamericanas cuyos inicios literarios tuvieron lugar en la primera mitad del siglo XX.

Delmira Agustini, destacada poeta adscrita al movimiento modernista, nació en Montevideo en 1886 y formó parte de la llamada generación de 1900, junto a Rubén Darío entre otros. Su poesía, de un fuerte erotismo muy original, expresa un hondo anhelo de libertad que escandalizó a la sociedad burguesa de su época. Delmira murió asesinada a manos de su ex marido, cuando sólo contaba con veintisiete años de edad. En su primer libro publicado, El libro blanco (Frágil) (1907), Delmira se adentra en la sensualidad y la espiritualidad. Uno de estos poemas, "Íntima”, refleja una visión de la felicidad que tiene que ver con la fusión amorosa, con un ideal de unidad soñado:

\footnotetext{
Hoy abriré a tu alma el gran misterio; Ella es capaz de penetrar en mí.

En el silencio hay vértigos de abismo:

Yo vacilaba, me sostengo en ti.

Muero de ensueños; beberé en tus fuentes

Puras y frescas la verdad: yo sé

Que está en el fondo magno de tu pecho

El manantial que vencerá mi sed.

Y sé que en nuestras vidas se produjo

El milagro inefable del reflejo...

En el silencio de la noche mi alma

Llega a la tuya como un gran espejo.
}

La meta amorosa de unión física y espiritual se presenta como la culminación del ansia de felicidad, que se proyecta en el otro. El otro se concibe como apoyo, sostén y camino. La antigua metáfora de la fuente donde saciar la sed aparece de modo intenso y pasional descrita como el fondo del pecho del amado. Dos seres que se unen bajo el eterno milagro del amor, mientras el alma de la poeta se va aproximando al alma de su amado, dispuesta, como un gran espejo, a reflejarlo.

Juana de Ibarbourou, nacida en Melo (Uruguay) en 1892, tuvo una infancia muy feliz, según afirmaba ella misma. Como poeta alcanzó los mayores honores y reconocimientos, siendo uno de los entrañables el otorgamiento del título "Juana de América" en 1929. Le fue concedido asimismo el Premio Nacional de Literatura, siendo la primera mujer en recibirlo. En su libro Las lenguas de diamante (1919), que publicó con apenas veintidós años de edad, Juana introduce la temática de elogio del cuerpo y fusión con la naturaleza, con una visión natural y brillante. En su poema "La hora", que 
renueva el tópico literario del Carpe diem, la autora describe la felicidad de aprovechar el momento presente, sin pensar en el incierto futuro:

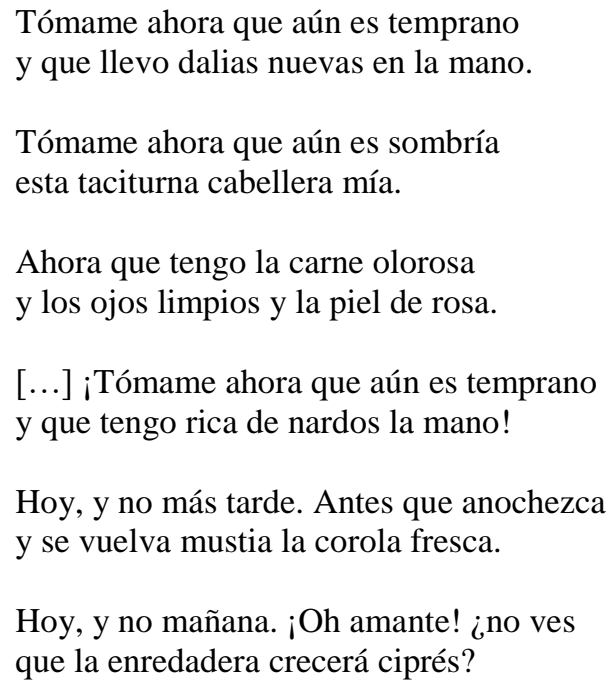

De Ibarbourou describe una felicidad carnal y gozosa ligada al frescor de la juventud, cuando el vigor y la belleza se encuentran en su máximo apogeo. Son muchas las imágenes que ligan el propio cuerpo a la naturaleza, sobre todo a las plantas y los árboles. Así, la poeta habla de dalias, rosa, nardos, corola, enredadera, ciprés... Todos estos símiles ofrecen la sensación de unión con la naturaleza y refrescan la idea de que somos uno con todos los demás elementos del cosmos. El entusiasmo de disfrutar del instante fugaz impregna los versos, animando a gozar intensamente de la lozanía y del amor, como parte imprescindible de la felicidad personal, lejos de falsas composturas y arrepentimientos tardíos.

Dulce María Loynaz, nacida en La Habana en 1902, fue abogada y Doctora en Leyes. En la década de los treinta estableció estrecha amistad con Federico García Lorca, Juan Ramón Jiménez, Alejo Carpentier, Carmen Conde y otros destacados intelectuales. Fue miembro de honor del Instituto de Cultura Hispánica, miembro numerario de la Academia Cubana de la Lengua y miembro correspondiente de la Real Academia Española de la Lengua. En su libro Versos (1938), que recoge su poesía escrita entre 1920 y 1938, Dulce María incluye su poema "La oración de la rosa", en el que desgrana sus deseos de felicidad y bienestar a través de una rosa:

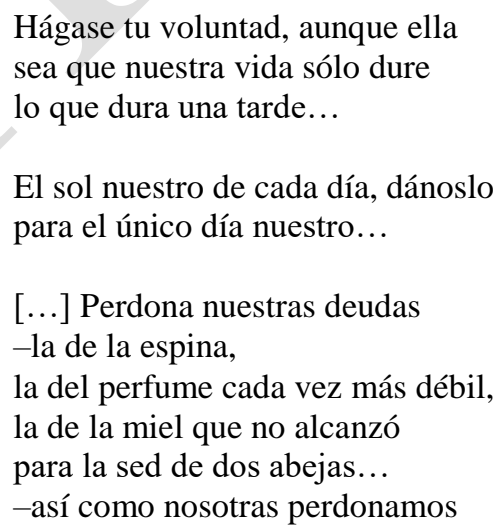


a nuestros deudores los hombres,

que nos cortan, nos venden y nos llevan

a sus mentiras fúnebres,

a sus torpes e insulsas fiestas...

La poeta adopta la voz de una personalizada rosa para dar su punto de vista sobre el bien y el mal que la rodea. De este modo, hace una denuncia de la injusticia social, en la que unos hombres cortan, venden y mienten, mientras otros -las rosas- son sistemáticamente ultrajados. La poeta pide sol, aunque sea consciente de la brevedad de la vida, como metáfora de la luz (tanto la luz física imprescindible para vivir, como la luz de la justicia sin la cual no es posible una existencia digna y plena). Pide perdón por las espinas, o debilidades humanas, y apuesta por un mundo sin mal, donde reine siempre el bienestar también para los más débiles.

\section{Conclusiones}

La búsqueda de la felicidad es uno de los grandes motores de la existencia humana, y como tal supone un leitmotiv recurrente en la literatura universal, así como en la creación poética. Durante el siglo XX, el rol social de la mujer se fue paulatinamente volviendo más activo e igualitario, hecho al cual coadyuvaron las luchas feministas y una toma de conciencia muy definida por parte de muchas intelectuales desde finales del siglo XVIII. Por lo que respecta a la poesía en español escrita por mujeres, son muchas las poetas de América Latina y de España quienes promovieron con su obra una mayor dosis de equidad entre géneros. Un buen exponente de ello es el concepto de felicidad que expusieron y promulgaron, reivindicando abiertamente una mayor libertad íntima y colectiva. El concepto de felicidad está indeleblemente ligado a la construcción identitaria personal y ha evolucionado cualitativamente con la incorporación masiva de la mujer al ámbito público y social. Las seis poetas mencionadas en este estudio suponen un inmejorable ejemplo de esta evolución.

\section{Referencias bibliográficas}

Agustini, D. (1907): El libro blanco (Frágil). Montevideo, O. M. Bertani.

Figuera AYMERICH, A. (1948): Mujer de barro. Madrid, Afrodisio Aguado.

IBARbourou, J. de (1919): Obras completas. Madrid, Aguilar.

Lanseros, R. - Merino, A. (2016): Poesía soy yo. Poetas en español del siglo XX (1886-1960). Madrid, Visor.

LOYNAZ, D. M. ${ }^{\text {a }}$ (1938): Versos. La Habana, Imp. Úcar García.

MÉNDEZ, C. (1928): Surtidor. Madrid, Imprenta Argis.

RoDRÍGUEZ, J. C. (1990): Teoría e historia de la producción ideológica. Madrid, Akal.

Russell, B. (1930): La conquista de la felicidad. Trad. Juan Manuel Ibeas. Barcelona, Debolsillo, 2002.

SÁnchez SAornil, L. (1996): Poesía. Ed. Rosa María Martín Casamitjana. Valencia, Pre-Textos. 